\title{
TCOM \\ Datafictions: or how measurements and predictive analytics rule imagined future worlds
}

\section{Gernot Rieder and Thomas Völker}

\begin{abstract}
As the digital revolution continues and our lives become increasingly governed by smart technologies, there is a rising need for reflection and critical debate about where we are, where we are headed, and where we want to be. Against this background, the paper suggests that one way to foster such discussion is by engaging with the world of fiction, with imaginative stories that explore the spaces, places, and politics of alternative realities. Hence, after a concise discussion of the concept of speculative fiction, we introduce the notion of datafictions as an umbrella term for speculative stories that deal with the datafication of society in both imaginative and imaginable ways. We then outline and briefly discuss fifteen datafictions subdivided into five main categories: surveillance; social sorting; prediction; advertising and corporate power; hubris, breakdown, and the end of Big Data. In a concluding section, we argue for the increased use of speculative fiction in education, but also as a tool to examine how specific technologies are culturally imagined and what kind of futures are considered plausible given current implementations and trajectories.
\end{abstract}

Keywords

Public engagement with science and technology; Risk communication; Science and technology, art and literature

DOI

https://doi.org/10.22323/2.19010202

Submitted: 12th September 2019

Accepted: 2nd December 2019

Published: 27th January 2020

Introduction

Our world is changing rapidly and profoundly. In ever more contexts, computers, sensors, and software are taking command. What can be observed is the gradual replacement of human decision making with algorithmic systems that guide and govern everyday life. What people buy, read, or watch, how doctors diagnose, the police operate, or judges judge, whether someone qualifies for a job, a loan, or an education - to an increasing degree, modern society is permeated by 'smart' digital technologies that shape and control our collective and individual futures.

The changes society is undergoing are not easy to grasp. Throughout the past years, the computerization of everything has progressed at breakneck speed, 
effectively outpacing our ability to carefully reflect, debate, and legislate. More recently, and in part as a reaction to the excitement around Big Data [see Mayer-Schönberger and Cukier, 2013], one can, however, observe the development of a critical discourse, with a growing body of literature - both academic and otherwise - examining the pitfalls of a "scored society" [Citron and Pasquale, 2014] in which automated systems rank and rate individuals without pause or limit. Primary concerns range from issues around privacy and surveillance [see Lyon, 2014] over the potential negative effects of algorithmic bias and discrimination [see $\left.\mathrm{O}^{\prime} \mathrm{Neil}, 2016\right]$ to questions around transparency and accountability [see Pasquale, 2015], all with a strong focus on the here and now, the problems and challenges of our early $21^{\text {st }}$-century digital situation. What tends to receive less attention, however, are possible longer-term developments and related cultural shifts - thoughtful inquiries into the what if rather than the what is. In a time marked by a constant state of anticipation, of "thinking and living toward the future" [Adams, Murphy and Clarke, 2009, p. 246], we concern ourselves remarkably little with the prospect of becoming an increasingly datafied, software-regulated society, dominated by the dictates of algorithmic gods.

One reason for the lack of critical engagement with all but the most immediate consequences of widespread computerization is that the contours of our digital future are still blurry and unclear. As indicated, the pace of ICT-led innovation is high, with new products and services launching every day [see Jaruzelski, Staack and Shinozaki, 2016], multi-sided business models challenging established customer-vendor relationships [see Goodman, 2016], and legislation not only lagging behind, but also quite different in different parts of the world [see DLA Piper, 2017]. Factors such as these add volatility and increase uncertainty, making future developments both hard to predict and difficult to discuss. ${ }^{1}$ Nevertheless, as scholars of Science and Technology Studies (STS) have emphasized, the ability to engage in forward-looking deliberation is vital for a healthy democratic system that assumes responsibility and prepares for the potential long-term implications of wider socio-technical change [e.g., see Michelson, 2016]. Rather than seeking accurate predictions, however, such anticipatory modes of governance are said to require a broad societal capacity to "collectively imagine, critique, and thereby shape issues presented by emerging technologies before they become reified in particular ways" [Barben et al., 2008, pp. 992-993]. Consequently, a more proactive approach to engaging with our algorithmic future would necessitate the cultivation of a critical imaginative gaze that a) contextualizes new technologies within plausible future scenarios, b) illustrates the different ways in which these technologies could evolve, c) opens up technological trajectories to considerations of social desirability, and d) develops robust capacities to deal with - and thus govern - unforeseen consequences and events [see Karinen and Guston, 2010].

In an effort to contribute to a greater future consciousness, this article examines a particular kind of literature - speculative fiction - asking whether, or in what ways, the stories and narratives presented may encourage reflective engagement with, and a better understanding of, the possible detrimental ${ }^{2}$ effects of expanding

\footnotetext{
${ }^{1}$ For two classic versions of this argument, see Toffler [1970] and Collingridge [1980].

${ }^{2}$ Of course, the application of advanced data analytics entails not only risks but also opportunities. This article neither denies this nor argues for a return to an analog age. Yet, given the rate and scale of digital transformation, it advocates for raised awareness that certain gains and benefits may come at a cost. To work towards a better understanding of the nature of these costs should not be interpreted as
} 
algorithmic regulation. While our review of works of fiction does not follow a strict analytical framework, our focus lies on power relations and their technology-provoked renegotiation. What functions do these technologies fulfil? What laws do they follow? What status do they acquire? What hierarchies do they impose? The paper is intended as a discussion starter rather than a definitive study or guide, arguing for the value of fiction as a tool for critical reflection and providing ideas for "what to read and watch before the robots take over" [Bergstein, 2017]. The article is structured as follows. First, section 2 defines and discusses the notion of speculative fiction, providing some conceptual clarifications while comparing it to its sister term science fiction. Section 3 then introduces the notion of datafictions as an umbrella term for speculative stories that deal with the datafication of society in imaginative ways. In section 4, we outline and briefly discuss fifteen datafictions, subdivided into five main categories: surveillance; social sorting; prediction; advertising and corporate power; hubris, breakdown, and the end of Big Data. In a concluding segment, we argue for the use of speculative fiction in education, but also as a tool to uncover and examine collective socio-technical imaginations inscribed into the spaces and places of various brave new worlds.

\section{On speculative fiction}

The term "speculative fiction" has a long and contested history. Its origins are usually traced back to an 1889 issue of Lippincott's Monthly Magazine, where two then-recent publications - Edward Bellamy's novel Looking Backward 2000-1887 and George Parsons Lathrop's short story The New Poverty - were described as "speculative fiction put in the future tense" [Egan, 1889, p. 597]. The notion was further popularized by the American author Robert A. Heinlein, who stated that he would "prefer the term to science fiction", stressing its ability to better capture the field's concern with "sociology, psychology, [and] esoteric aspects of biology" [Heinlein, 1989, p. 49]. Heinlein was careful, however, to differentiate speculative fiction from fantasy, arguing that the former would "rul[e] out the use of anything as material which violates established scientific fact, laws of nature [...], i.e., it must be possible to the universe as we know it" [1989]. In a similar vein, Margaret Atwood, acclaimed author of several dystopian novels, has shown reluctance to classify her work as science fiction, where "things happen that are not possible today", instead favoring speculative fiction as a label for prose where "nothing inconceivable takes place, and the projected trends [...] are already in motion" [Atwood, 2005b, p. 92]. As Atwood explains, "We've done it, or we're doing it, or we could start doing it tomorrow" [2005b].

While Atwood's attempt to position speculative fiction as a genre separate from and opposite to science fiction has not gone unchallenged [see Le Guin, 2009], the distinction draws attention to the issue that much of what is commonly considered science fiction involves dubious plots and technologies that have no or very little connection to the world we live in. The problem is not so much a lack of realism, but a missing cognitive link between the imagined and the actual, a sense that in one way or another, what could happen there could also happen here [see Atwood, 2011]. Such a link can be rather abstract or 'on the nose', but it is only through jolts

a sign of innovation-blocking technophobia, but as a way of preparing for and navigating an already highly technologized world - and, presumably, future [see Callon, Lascoumes and Barthe, 2009, (2001); Felt, 2015]. 
of recognition - e.g., engendered by historical, cultural, or technical references and associations - that fictional tales acquire a deeper meaning and purpose, effectively generating "other worlds as a comment upon our own" [Miner, 1991, p. 150]. As Atwood [2005b, pp. 158-159] emphasizes, "The fictional world so lovingly delineated by the writer may bear a more obvious or a less obvious relation to the world we actually live in, but bearing no relation to it at all is not an option." Ultimately, it is by drawing such connections that speculative fiction "take[s] part in the discourses of the contemporariness" [Kuźnicki, 2017, p. 18], raising questions "not only about what might happen, but also about what is happening" [Miner, 1991, p. 150].

Given this focus on plausible stories ${ }^{3}$ grounded, at least to some extent, in human history and experience, it should come as no surprise that the genre often addresses issues quite similar to those of real-life society: the unequal distribution of power, wealth, and privilege; the violation of civil rights and liberties under systems of oppression; racism, sexism, and other forms of social discrimination; environmental change and human interference with nature; the potential risks and harms of techno-scientific innovation, to name but a few. Yet, rather than directly dealing with the here and now, speculative fiction explores these issues in alternative realities, pushing them to extremes in "strange but imaginable" future contexts [see Onyett, 2016, p. 62]. Such visions can then serve as "dire warnings [... ], dark shadows cast by the present into the future" [Atwood, 2005b, p. 94]. They are, figuratively speaking, "what will happen if we don't pull up our socks" [2005b]. By showing what it might be like to live in such a universe, speculative novels may stimulate reflection and promote critical thinking, providing "rich and complex avenues for reading and rereading the world" [see Thomas, 2013, p. 4]. What is important here is the interaction between the narrated story and the reader. As de Smedt and de Cruz [2015] argue, speculative fiction's epistemic value lies in its ability to present fictional worlds in great detail, immersing the reader in an altered reality and allowing her to become emotionally invested in a concrete situation or event. Furthermore, by showing new technologies fully operational and graphically depicting what changes in social organization could mean for those affected, the genre can contribute to a better appraisal of the actual consequences such hypothetical situations may have, should they ever occur. It is for these qualities that speculative text has been lauded as a valuable resource for critical pedagogy [see Patch, 2014], public deliberation [see Milkoreit, 2017], but also technology assessment [see Miller, 2015], providing opportunities for developing a sense of "informed skepticism" while exploring the "social, political, and ethical implications of science [and technology] that are so powerfully revealed through story" [Sveck and Winiski, 2013, p. 37].

The notion of speculative fiction as outlined above has guided our literature review in several important ways. On the one hand, it has prompted us to discard any fictional stories that bear no or hardly any resemblance to the world and universe as we currently know it. Thereby, the cut-off point was not whether the story features space travel and aliens or not - a distinction Atwood makes when differentiating between sci-fi proper and speculative fiction [see Atwood, 2011, p. 115] - but rather the degree to which the topics and issues addressed connect to

\footnotetext{
${ }^{3}$ The focus on plausibility resonates with literature from the broader field of Science and Technology Studies on future making as exemplified in Selin's [2011] work on scenario development in the field of nanotechnology, which specifically aims to create "plausible visions".
} 
our own history and culture. For instance, despite its space-age setting, it is the thematization of mathematical prediction and science as a religion that makes Isaac Asimov's [2010a] Foundation trilogy such a striking illustration of today's Big Data-invigorated social physics movement [see Strogatz, 2004; Pentland, 2014]. Thus, while lacking in sociological realism, the series offers a quintessential portrayal of an enduring positivist dream ${ }^{4}$ - i.e., to uncover the invariant, 'natural' laws of collective human behavior [see Ball, 2002] — providing an imaginative take on a field and vision that has gained considerable traction in recent years. On the other hand, the flexibility of the genre has also allowed us to include fictions that are so close to home they can hardly be considered sci-fi. Examples for this are Wilson's [2015] novel The Affinities, Eggers' [2013] tech thriller The Circle, or Liu's [2012] short story The Perfect Match. None of these titles include technologies that either have not already been realized or else could not conceivably be realized at any given moment. Instead, they ponder what it means to be human in ever more tech-regulated environments, creating unsettlingly familiar sceneries and then "pushing the envelope as far as it will go" [Atwood, 2005a]. What can be observed in such cases is a progressing conflation of fiction and reality, sometimes to the point where the fiction - even if recent - appears to fall behind the actual pace of techno-cultural change. This does not, however, imply that fictional tales are becoming irrelevant as tools for critical assessment and reflection, but rather, as Atwood [2005a] argues, that exploring the imagination must no longer be considered a pastime, but a necessity, because "increasingly, if we can imagine it, we'll be able to do it."

Subsequently, this paper provides insight into what can broadly be subsumed under the label of "datafictions". After some conceptual clarifications (section 3), we present a selective overview of works of fiction that may contribute to a deeper engagement with the logics and politics of spreading algorithmic regulation (section 4). While by no means comprehensive or conclusive, this review hopes to serve as a starting point and guide for researchers, educators, and readers who wish to delve further into the subject matter.

Datafictions: conceptual and methodological considerations
Whereas speculative fiction functions as a basic framing for the kind of literature we are interested in, the notion of "datafictions" further specifies our thematic interest. In short, we propose datafictions as an umbrella term for speculative stories that deal with the datafication of society in both imaginative and imaginable ways. ${ }^{5}$ While this definition is fairly broad, so is the range of topics and issues commonly addressed: questions of surveillance and control, the use of predictive analytics, the emergence of new reputation economies, the intricate politics of computer-curated information, the development of sophisticated AI systems, or society's growing dependence on technology and machines are but some of the subgenre's most prevalent themes. Many of these stories are bleak and dystopian, depicting the oppressing force of all-knowing totalitarian regimes, while others are more satirical and playful, commenting, for instance, on people's tendency to

\footnotetext{
${ }^{4}$ Others have referred to it as the "Cartesian dream" [see Pereira and Funtowicz, 2015].

${ }^{5}$ The notion of "datafictions" has been used in various academic and non-academic contexts to capture and describe different phenomena. While we cannot provide a comprehensive list of previous uses, we do wish to acknowledge Sturgeon's [2015] embrace of "data-fictions" as a digital storytelling method for speculative designers, which differs from our use of the term as an analytical lens for exploring speculative fiction.
} 
overshare personal information or to rank and rate anything that can possibly be rated and ranked. At their core, however, most stories are quite serious interrogations of techno-cultural dynamics and trends, inviting the reader not only to consider but to experience possible future scenarios through a protagonist's eyes and actions. Thereby, questions of power, autonomy, and identity may become much more tangible and 'real', effectively replacing abstract concepts with something that can feel uncomfortably close and personal. Narrative fiction may thus prove fertile ground for a more critical appreciation of data as a source of social order and control, their collection and analysis a key instrument of modern population management. What datafictions can then ultimately provide are vivid accounts of data power in action - the concrete practices, the laws and ethics, the immediate but also the long-term societal repercussions. Although imagined, these accounts may serve as a basis for further reflection, essentially acting as a diffracted window to our own culture and time.

When selecting the body of work for analysis, we looked for speculative fictions that could be considered culturally resonant and thus may serve as valuable resources for (collective) reflection and deliberation. Being aware of the intricacies of defining the boundaries of what counts as culturally resonant, we chose to apply a stepwise selection approach. After picking a number of well-known genre classics, we added more recent literature by assessing the culture and literature sections of news outlets such as The New York Times, The Guardian, ArsTechnica, and The Verge. We furthermore used dedicated blogs and online forums for gathering material for analysis and engaged in personal conversations with scholars familiar with the subject matter. Apart from broader cultural resonance, we decided to focus on literary and audio-visual texts - i.e., novels, short stories, films, and television shows - that examine the impact of technology on people's lives, the formative power these technologies can have, but also potential forms of resistance, if only to show their utter futility. ${ }^{6}$ All in all, we present and briefly discuss fifteen datafictions, most of them of a decidedly dystopian, techno-nightmarish nature. The classification of the texts into five sub-categories is the outcome of a deep, iterative reading process, guided by a coding framework [Srivastava and Thomson, 2009] that allowed us to structure, compare, and contrast the fictions' central ideas and relate the storylines to current issues and debates. Concerns related to surveillance (section 4.1), social sorting (4.2), prediction (4.3), corporate power (4.4), or hubris (4.5) have been voiced and discussed extensively in the social science and humanities literature, a strand of research and debate we have contributed to elsewhere [Kovacic, Strand and Völker, 2019; Rieder and Simon, 2016]. ${ }^{7}$ As indicated, the resulting overview is neither exhaustive nor definitive, but rather seeks to provide some initial orientation and impetus for further exploration.

\footnotetext{
${ }^{6}$ In fact, many stories - after allowing for initial bursts of hope and optimism - eventually lead to the pessimistic conclusion that the reigning regime cannot be weakened or overthrown and that resistance, under Big Brother's watchful gaze, is indeed futile.

${ }^{7}$ A detailed overview of the academic literature engaging with issues of Big Data and "algorithmic regulation" [Yeung and Lodge, 2019] is beyond the scope of this paper. As a starting point, however, Boyd and Crawford's [2012] Critical Questions for Big Data and Kitchin's [2014] Big Data, New Epistemologies and Paradigm Shifts provide accessible introductions to the debate from a social science perspective. For a more philosophical account, see Mittelstadt et al.'s [2016] The Ethics of Algorithms: Mapping the Debate.
} 
There are two notable omissions in our selection. First, though extremely popular, we are excluding stories about artificial intelligence (AI) if AI is discussed in terms of machine consciousness and linked to ethical debates about robot rights and human-like emotions. Why so? On the one hand, while existing computational models have successfully captured a number of cognitive and behavioral correlates of conscious information processing, to date, "no existing approach to artificial consciousness has presented a compelling demonstration of phenomenal machine consciousness, or even clear evidence that phenomenal consciousness will eventually be possible" [Reggia, 2013, p. 112]. Given this, many fictional treatments of AI - think of the HBO series Westworld (2016), the sci-fi thriller Ex Machina [2014] or the robot drama A.I. Artificial Intelligence [2001] — reside in the realm of fantasy rather than plausible speculation. On the other hand, we would argue that the focus on consciousness - regardless of whether rationally conceivable or not - diverts attention from other AI-related issues that are already evident, and arguably much more pressing. As one news headline poignantly put it, "Intelligent robots don't need consciousness to turn against us" [del Prado, 2015]. A second, related omission concerns fictions of an oncoming singularity depicted as a runaway, self-improving superintelligence that far exceeds the human mind and intellect. More often than not, these rogue systems then strive to either enslave — as seen in, e.g., I, Robot [2004], The Matrix [1999], Colossus: The Forbin Project [1970] — or eradicate - e.g., Robopocalypse [D. H. Wilson, 2011], Computer One [Collins, 1993], The Terminator [1984] — humanity, no longer following the will of their increasingly obsolescent creators. While such visions might make for an entertaining plot, AI experts have argued that they rest on a "profound misunderstanding of both the nature of intelligence and the behavior of recursively self-augmenting systems" [Chollet, 2017], stressing that the development of artificial general intelligence (AGI) remains a far-off pipe dream. A more realistic scenario, one depicted in many of the datafictions mentioned below, is the continued proliferation of comparatively narrow, specialized AI into virtually all corners of society. Importantly, however, these imagined AI systems are seldom rogue or beyond human control, but serve specific purposes driven by certain government or corporate interests and objectives. Neither conscious nor ultrasmart, the technologies showcased in the selected fictions are often surprisingly mundane, concurring with Atwood's aforementioned warning: "We've done it, or we're doing it, or we could start doing it tomorrow" [2005b, p. 92].

Datafictions: a selective overview

\subsection{Surveillance}

The rise of Big Data has been accompanied by renewed interest in a classic of dystopian fiction — George Orwell's [1987, (1949)] novel Nineteen Eighty-Four. In a world where Big Brother watches one's every move, private life has effectively come to an end. Through always-on telescreens and hidden microphones, the one-party government has turned society into an electronic panopticon: "[a]sleep or awake, working or eating, indoors or out of doors, in the bath or in bed - no escape" [1987, p. 29]. While Orwell's vision also connects to recent debates around fake news and alternative facts [see Andrews, 2017], in the main, it provides a chilling depiction of life under constant surveillance, showcasing possible consequences such as the loss of individuality in a culture marked by distrust, emotional solitude, self-censorship and enforced conformity. What is more, the book offers a haunting illustration of the use of technological progress for the 
diminution of human liberty, sensitizing the reader to the interrelationship between (ICT) technology, surveillance, and social control. Consider the following excerpt indicating how intimate and fine-grained such tech-enabled surveillance in Orwell's post-World War II fiction has already become: "He [...] pushed back his chair, so as to get as far away from the telescreen as possible. To keep your face expressionless was not difficult, and even your breathing could be controlled, with an effort: but you could not control the beating of your heart, and the telescreen was quite delicate enough to pick it up" [Orwell, 1987, p. 82].

Moving from state to corporate surveillance, Dave Eggers' [2013] novel The Circle chronicles the rise of a data-hungry tech company and its rapid growth in influence and power. As a Google-Facebook-Twitter hybrid that has already devoured most of its competitors, the eponymous Circle seeks "full access to all data about every person" [2013, p. 483], employing a growing variety of sensors and services to create a society where "secrets are crimes" [2013], "privacy is theft" [2013, p. 303], and "all that happens must be known" [2013, p. 67]. While the novel delves into the social and psychological consequences of extreme metrification and social media pressure, it also considers the effects of privately-controlled transparency on democracy, showcasing how the quest for improved political accountability can lead to an utter totalitarian nightmare. In general, it is this emphasis on the recurring gap between good intentions and bad solutions that makes The Circle an intriguing, provocative read: Child abduction is a horrible crime, but does this warrant the implantation of miniature tracking chips into each and every kid? More data may allow for better healthcare, but does this sanction a mandatory, round-the-clock monitoring of one's personal life? Back-room deals can undermine people's trust in public officials, but does this mean that officeholders should be forced to 'go clear', live streaming all of their meetings and conversations to an unrestricted public audience? What the Circle's followers dream of is a "new glorious openness, a world of perpetual light" [2013, p. 491]; what they help create, however, is "the world's first tyrannical monopoly", a "private company [controlling] the flow of all information" [2013, p 401].

Another dark vision of pervasive corporate surveillance is outlined in Ken Liu's [2012] short story "The Perfect Match". In a world not too far from our own, people largely rely on personal AI assistants to manage their lives - what to eat, where to shop, how to relax, whom to date, Centillion's proprietary algorithms "always know best" [2012]. The reason the software can provide such spot-on recommendations is its unrestricted access to personal information, including users' social media profiles, their complete search and purchase histories, any reviews they may give or receive, location data, audio and video streams, et cetera. All of these data are then used to compile user profiles, train personalized learning algorithms, and nudge people into commercial transactions, with the aim of boosting advertising revenue. What Liu's story highlights, however, is that most people give up their data voluntarily, either unaware of the end user agreement terms and conditions, or else willingly accepting a loss of privacy and autonomy in exchange for better products and services. The life Liu describes is one filtered through the eyes of the machine, turning people into "docile", "obedient puppets" who have forgotten how to think and judge for themselves: "Look at you. You've agreed to have cameras observe your every move, to have every thought, word, interaction recorded in some distant data center so that algorithms could be run over them, mining them for data that marketers pay for. Now you've got nothing left that's 
private, nothing that's yours and yours alone. Centillion owns all of you. [...] You buy what Centillion wants you to buy; you read what Centillion suggests you read; you date who Centillion thinks you should date. But are you really happy?" [2012].

\subsection{Social sorting}

While processes of social sorting already play a role in the surveillance dystopias mentioned above, they figure more prominently in other fictions, a first example being Aldous Huxley's [2006, (1932)] canonical novel Brave New World. Whereas Orwell's Nineteen Eighty-Four envisions a violent totalitarian dictatorship, Huxley depicts a subtler, more mechanical system of social oppression. In a distant future, attempts to create an utmost efficient and stable society have led to an eradication of individuality and free will. People are bred into one of five castes, each chemically engineered and psychologically conditioned for specific, predefined tasks and duties: intellectually challenging jobs for smart-by-design Alphas, "semi-moron work" for artificially backward Epsilons - "the principle of mass production at last applied to biology" [2006, p. 7]. Rather than forcefully suppressed, however, caste members are nudged into a life of self-indulgence and complacency, nurtured by a nonstop stream of moral propaganda and consumption-driving advertisement. In Huxley's vision, social order thus follows industry interests, the happy, goods-consuming citizen an effective solution to the need that the "machine turns, turns and must keep on turning" [2006, p. 42]. Under-consumption, in turn, is seen as a "crime against society" [2006, p. 52], a failure to commit and conform to "what civilized people ought to do" [2006, p. 122]. Sprinkled with a good dose of irony, what makes Brave New World a particularly commendable read is the attention devoted to the protagonists' emotional states as well as intense debates arguing the pros and cons of the imposed system, signifying a veritable culture clash. As the Savage, born and raised in an Indian reservation, responds when reminded of the comfort the highly regulated life affords: "But I don't want comfort. I want God, I want poetry, I want real danger, I want freedom, I want goodness. I want sin. [...] I'm claiming the right to be unhappy." [2006, p. 240]

The vision of a society ruled by measurements and metrics is also played out in the Black Mirror TV episode "Nosedive" [Wright, 2016]. Using a centralized reputation system, the people in this fiction constantly rank and rate each other's behavior and social media feeds, the aggregated score becoming a public statement of one's status and standing within the community. A high score means not only social prestige, but also access to better jobs and exclusive discounts. A low score, on the other hand, can endanger one's very existence, threatening career prospects as well as acceptance in society. The episode pictures people's constant struggle to maintain their scores, the apparent need to create and hide behind a fake, always-smiling persona, and the relative ease with which carefully built reputations can be destroyed by a few unfortunate events. While the software technically enables this culture of vigorous grading, it is the people themselves who fuel the system's cruelty: Though friendly on the surface, they have turned into hypersensitive critics of their peers, obsessed with "play[ing] the numbers game" because "that's how the fucking world works" [2016]. What is thus most interesting about "Nosedive" is not so much the details of the technology, but the story's inquiry into human nature, exposing our need to judge and compare, 
thereby always looking for approval and self-validation in the form of likes, upvotes, and 5-star ratings. And while the episode's cinematography paints the world and its people in bright pastel colors, it soon becomes clear that there is something very rotten about the state of this imagined civilization.

The theme of computerized social sorting is also explored in Robert C. Wilson's [2015] novel The Affinities. When the data-mining company InterAlia offers Affinity testing as a new service, the world starts to change. Based on a series of psychological assessments, people who qualify are placed in one of twenty-two Affinity groups where someone is "statistically more likely to trust others, to be trusted, to make friends, to find partners, in general to have successful social engagements" [2015, p. 15]. While such groups can be physically, ethnically, and socially diverse, the members of an Affinity share certain character traits that facilitate interpersonal bonding, fellowship, and cooperation. Within but a few years, Affinity circles start to revolutionize societal dynamics: people distance themselves from their families and friends, preferring the company of their "tranchemates" instead; commercial networks become increasingly tribal, with Affinity groups managing their own trusts and investment portfolios; political decision making, too, gets shaped by Affinity interests, a growing number of elected officials firmly in the pocket of powerful clan lobbies. What Wilson outlines is a post-national system of loyalty that shakes the very foundations of a society and culture. While also tackling questions of privatization and intellectual property, the book's central theme is that of algorithmic discrimination and social exclusion. Whereas acceptance to an Affinity group comes with a wide range of tangible benefits, those who do not qualify are left behind, locked out of the exclusive enclaves of their former peers: "You could put a hundred people together and they could live better, fuller, freer, happier, more collaborative lives - but only the right hundred people, not a hundred random people off the street. [...] Not disputing it's nice inside, for anyone who can get inside. But think about what that means for all the people not included" [2015, p. 239f].

\subsection{Prediction}

The collection and statistical analysis of data is often driven by the goal to forecast trends and events. How likely is it that a particular recommendation will suit the recipient's tastes and preferences ("The Perfect Match")? What are the probabilities that a person will fit into a specific group of likeminded people (The Affinities)? While predictive capacities play a role in many datafictions, there are some that treat the theme as a central subject matter. In Isaac Asimov's [2010a, (1951); 2010b, (1952); 2010c, (1953)] Foundation trilogy, for instance, a scientist named Hari Seldon develops a branch of mathematics that allows him to accurately predict the future course of history. Having foretold the slow demise of the Galactic Empire, Seldon and his followers are cast into exile on a far-off planet where they attempt to preserve humanity's knowledge and rebuild the interstellar civilization. What is interesting is that only the first few chapters follow the actions of Seldon himself, the bulk of the books depicting crises and challenges of later generations, all perfectly predicted by the doctor's initial calculations. After a while, however, an unforeseen anomaly causes Seldon's predictions to fail, casting doubt on what was considered a proven destiny. The space saga then engages in a critical examination of a probabilistic science that assumes that "the laws of history are as absolute as the laws of physics" [2010a, p. 283], pondering issues of blind trust, free will, and 
the limits of mathematical (pre)calculation. Importantly, however, Asimov's series is not a cautioning dystopia, but a complex fictional treatment of the longstanding human aspiration to know ahead and plan in advance. And it is arguably this absence of overt moralizing that makes the series a particularly productive, albeit controversial [Krugman, 2012], discussion piece.

The theme of prediction and foresight also plays a central role in Philip K. Dick's [1991, (1956)] short story The Minority Report. In a fictional New York City, police forces make use of the Precrime system to detect and detain citizens who are prophesied to commit a crime in the near future, thereby "successfully abolish[ing] the postcrime punitive system of jails and fines" [1991, p. 72]. As a result, felonies have been cut down by almost one hundred percent, creating an all but crimeless society in which acts of violence and aggression are largely unknown. But the practice of pre-emptive crime prevention raises some difficult questions: What are the rights of those incarcerated as the police are effectively "taking in individuals who have broken no law" [1991]? How accurate are the predictions, how secure is the system, and is there a danger of corruption? As a society, what do we value more: personal integrity or statistical safety? What Dick's thriller-like story furthermore outlines is the immense controlling power of the analytical machineries and those in charge of them. The situation is worsened as there seem to be hardly any accountability structures in place, the police and the military being the only organizations with access to the system's forecasts. Citizens are thus subjugated to a black-boxed security regime with no means to appeal or get information about the presumed future offense. Given the recent rise of predictive policing all over the world [Ferguson, 2017], Dick's Minority Report no longer seems like a distant fiction, but should rather be regarded as a very timely and relevant read.

Another example for society-wide pre-crime analysis can be found in the anime TV series Psycho-Pass [2012]. In a dystopian $22^{\text {nd }}$-century Japan, people are constantly monitored by the Sibyl system, a super computer architecture that analyzes people's psychological profiles to determine their crime coefficient. If the estimated score is above a certain threshold, the person registers as a latent criminal with all rights being immediately revoked. The system then commands "enforcement action", essentially ordering authorities to eliminate the subject even if no crime has yet been committed. While visualizing the violent cruelty of the system in genre-typical extremes, the series offers thoughtful reflections on issues of responsibility in complex human-machine entanglements. As an officer concedes after nearly having shot a panicked hostage the Sibyl system deemed to be a dangerous threat: "I've been an enforcer for a long time now. [...] Following orders and taking down preys engrained in me. My hands only know how to do what they are told, I've always obeyed [... ]. I've taken down many latent criminals. I did what was best for society, blindly accepting that idea. And one day I just stopped thinking about what I was doing. It all become perfunctory to me. As natural an act as breathing." [2012, episode 2] Alongside more general questions of justice and due diligence, the series also focuses on the importance of public trust, stressing that the system's acceptance crucially depends on people's belief in its flawless working and perfect objectivity: "They promised a society managed by fair and impartial machine intelligence, a law free of petty human ego. People only accepted Sibyl because that's what they thought they were getting." [2012, episode 17] Following the show's dark plot, it soon becomes clear that this is actually not quite what people were getting. 


\subsection{Advertising and corporate power}

Another central topic is that of targeted advertising and hyper-commercialization, Eggers' [2013] The Circle, Liu's [2012] “The Perfect Match", Huxley's [2006, (1932)] Brave New Word, and Black Mirror's "Nosedive" episode [Wright, 2016] being but a few examples already mentioned above. A particularly well-known depiction of targeted commercial content is shown in Steven Spielberg's film Minority Report [2002] — a loose adaptation of Dick's same-named short story — where the main protagonist is personally addressed by surrounding billboards that seem to be able to detect his emotional state (extreme stress) and suggest various forms of relief (having a drink, going on vacation). The idea of highly personalized advertising is also explored in Thomas Sweterlitsch's [2014] novel Tomorrow and Tomorrow, a gory crime story taking place ten years after a nuclear terrorist attack has completely obliterated the city of Pittsburgh. People in this fiction have started to wear brain-wired augmented reality interfaces that project overlays onto supplementary retinal lenses. While these interfaces are used to watch video streams and revisit memories of the past, the system constantly tracks people's location and field of view, serving up ads that fit the current situation: "Waverly dips a biscuit into his cappuccino. Illy pitches espresso in the Adware - I consent and soon our waiter brings a fresh cup and biscotti [... ]." [2014, p. 55] But the world of Tomorrow and Tomorrow is one defined by voyeuristic sensationalism and moral decline, the ads often linking to pornographic content matched to one's personal preferences: "I watch her a heartbeat too long after she returns to her game, her jersey dress rising with every punch, and my Adware fills with pop-ups and redirect streams to escort services and live companions, to cam girls in lingerie who coo they want to meet me. [...] 'I don't want any, I don't want them,' but the ads are better at knowing what I want than I am and ranks of girls march for my approval, all slight variations of Twiggy [...]" [2014, p. 22].

While fictions such as Tomorrow and Tomorrow focus on people's individual experience of personalized adverts, Frederik Pohl and Cyril M. Kornbluth's [2003, (1953)] classic novel The Space Merchants features a critical portrayal of the advertising industry as such, and the substantial influence and power this sector can wield. The story is as follows: On an overpopulated planet Earth, ad agencies who have become the de facto rulers of modern society are looking to expand their customer base, following the credo "more people, more sales" [2003, p. 94f]. But space on Earth is running out, with even the wealthy living in small, box-like apartments and both water and natural proteins being scarce, expensive resources. Marketing experts, though, have come up with a solution: To colonize Venus and turn the planet's inhabitable atmosphere into the home of a thriving, and thus exploitable, new civilization - an entire world to loot, gut, and plunder. To achieve this, however, people must be nudged into wanting to go to Venus, persuading prospective colonists but also society at large that "the grass is greener far away" [2003, p. 16]. Against this background, the book's twist-rich plot deals with a range of issues: the ad industry's constant hunger to grow and expand; a professional ethos and ethics guided only by the proverbial "god of Sales" [2003, p. 8]; the conflicting interests of producers and consumers in an economy geared toward profit maximization; a culture of lobbying where public officials are but puppets dancing to the strings of their corporate masters. The Space Merchants is not a recent publication, but in a world where the revenues of digital marketing companies 
dwarf the GDP of many nations [see Khanna, 2016], and where ad-selling social media platforms aim to connect ever more people to their version of the Internet [Shearlaw, 2016], the book seems more topical than ever.

The political influence of powerful tech corporations is also explored in Daniel F. Galouye's [1999, (1964)] novel Simulacron-3. In a society completely overrun by human pollsters, a company called Reactions, Inc. develops a computer simulation in which electronic avatars can be surveyed for their thoughts and opinions on advertised products. Since the simulated environment closely mimics that of its creators, the sampled reactions are indicative of a product's real-world performance: "Before we market a product, we want to know who's going to buy it, how often, what they'll be willing to pay" [1999, p. 8]. What soon becomes clear, however, is that the company's ambitions reach far beyond mere market research. First, by reprogramming the simulation from a market-focused to a politically-oriented environment, the company aims to support political leaders in their campaigns, telling them "which cards to play — in every national and local election and on every issue" [1999, p. 38]. Second, using the simulator for political advice, the company's CEO eventually plans to assume leadership himself, replacing current office holders with an industry-friendly cabinet: "Hall, I think you're observant enough to know I'm a man of no small ambitions. [...] What we want is the most capable national leadership available! Can you think of a bigger financial empire than the one I've created? Is there anyone more logically qualified to sit in the White House?" [1999, p. 56] Although published decades ago during the early years of the computer age, Galouye's book remains incredibly timely: Though the White House is not yet controlled by the CEO of a major tech company, media reports have documented the crucial role that consultancy firms have played in recent elections [Cadwalladr and Graham-Harrison, 2018], employing technology that is not too far from what is envisioned in Galouye's fiction. Given that Simulacron-3 also addresses the issue of automation-caused mass unemployment, the book certainly should not be missing from any datafictions reading list.

\subsection{Hubris, breakdown, and the end of big data}

Continuing with another classic of speculative fiction history, Edward M. Forster's short story The Machine Stops [2013, (1909)] envisions an extreme case of unmitigated technology dependence. In Forster's fiction, mankind has largely retreated to a subterranean habitat, with each individual residing in its own fully automated room, serviced by a giant machine structure. Direct personal interaction has become rare, with people mostly communicating through sound and image transmitting devices, unwilling to leave the comfort of their homes, where the machine provides them with any amenities needed - from food and clothing to medicine and hot baths to music and literature. In turn, though religion is generally frowned upon, people have started to worship the benevolent machine, gradually forgetting that it was man, not God, who once created it. Thus, while people have grown increasingly reliant on using and interacting with the machine, they no longer understand the apparatus as a whole, gradually losing the ability to control it: "We created the Machine, to do our will, but we cannot make it do our will now. It has robbed us of the sense of space and of the sense of touch, it has blurred every human relation and narrowed down love to a carnal act, it has 
paralyzed our bodies and our wills, and now it compels us to worship it" [2013, p. 30]. Ultimately, Forster's vision is a gloomy meditation on what is lost and left behind in the name of progress if thought of only in terms of technical advancement and the progress of the machine. It is a story about a decadent, complacent society that is swallowed by its own inventions: "Man, the flower of all flesh, the noblest of all creatures visible, man who had once made god in his image, and had mirrored his strength on the constellations, beautiful naked man was dying, strangled in the garments that he had woven" [2013, p. 39].

The theme of scientific hubris and out-of-control technology is also explored in Mary Shelley's [2012, (1818)] horror novel Frankenstein. After being forsaken by its creator and shunned by humanity, an unnamed artificial creature, kind-hearted and affectionate at first, turns into a murderous monstrosity, driven by feelings of hatred and revenge. While some chapters are told from the monster's perspective, the story mainly progresses through the eyes of its tormented creator, Victor Frankenstein, whose neglect and failure to assume responsibility greatly contribute to the creature's misery and wickedness. By pondering this father-child relationship, the tale raises questions that remain of crucial relevance in today's science and engineering culture: Are there any limits to what science and technology ought or ought not to do? What are the moral and ethical duties of a creator towards her invention and the possible effects this invention may have on society? Also, as for the most part it is only Frankenstein who is aware of the creature's evil deeds: What are the ill-effects of secrecy and non-disclosure? What structures of accountability could counteract such tendencies towards systematic concealment and opaque operations? Shelley's novel can thus be read as a call for prudence and caution, but also as a reminder that technologies, once unleashed upon society, must continually be watched and cared ${ }^{8}$ for should we not wish to experience their broken-hearted wrath: "'Remember, that I am thy creature; I ought to be thy Adam, but I am rather the fallen angel, whom thou drivest from joy for no misdeed. [... ] I was benevolent and good; misery made me a fiend. Make me happy, and I shall again be virtuous."' [2012, p. 85].

A final recommendation would be James Bridle's [2016] short story "The End of Big Data". In his text, Bridle sketches a world in which the collection and exchange of personal data has been banned by law. A sophisticated satellite system monitors earth, scanning infrastructure and transmissions to ensure that "all the mainframes that used to track and store every detail of [people's] lives are turned off, and stay off" [2016]. This is necessary because a new black economy aims to profit from whatever data are left to scrape, trading user profiles to sustain the remnants of the once thriving advertising industry. The ban of personal data was caused by a complete breakdown of the Web's networks, followed by large-scale data breaches: social security numbers, passwords, emails, text messages, browsing histories, credit card transactions, contracts, medical records - all public and for everyone to see. Everyone became vulnerable and legislature decided to act: "Nothing identifying. No dossiers, no manila files, no cookies or patterns of life or digital signatures, nothing that could link anyone to anything." [2016] Bridle's story is a thought experiment envisioning the end of the digital world as we currently know it, paying particular attention to the sites and physical objects left behind:

\footnotetext{
${ }^{8}$ For a more detailed discussion of Frankenstein and the significance of care, see Halpern et al. [2016]. For an analysis of collective imaginations and practices of responsibility in collaborative knowledge production, Völker [2020, forthcoming].
} 
decommissioned data centers, disassembled routers and cooling vents, drums of redundant Ethernet cable, recycling crews that scrap computer parts for metals, minerals, and magnets. If a personal data repository is discovered, it will be destroyed, for the people in Bridle's tale have experienced and rebelled against its power: "Data is power. It's something to take from and hold over somebody else; quantified dominion. The more you have on someone, the more you have over them. The more personal it is, the more power, until you've eaten right through the skin of social relationships and into the flesh itself. The [personal data repository] is an ark of unqualified dominion." [2016]

Table 1. Overview of selected datafictions.

\begin{tabular}{|c|c|}
\hline Theme & Name \\
\hline Surveillance & $\begin{array}{l}\text { - Nineteen Eighty-Four [novel] by George Orwell (1949) } \\
\text { - The Circle [novel] by David Eggers (2013) } \\
\text { - The Perfect Match [short story] by Ken Liu (2012) }\end{array}$ \\
\hline Social Sorting & $\begin{array}{l}\text { - Brave New World [novel] by Aldous Huxley (1932) } \\
\text { - Black Mirror - "Nosedive" [TV episode] Netflix (2016) } \\
\text { - The Affinities [novel] by Robert C. Wilson (2015) }\end{array}$ \\
\hline Prediction & $\begin{array}{l}\text { - Foundation Trilogy [book series] Isaac Asimov (1951-53) } \\
\text { - The Minority Report [novel] Philip K. Dick (1956) } \\
\text { - Psycho-Pass [TV series] Tow Ubukata (2012) }\end{array}$ \\
\hline Advertising \& Corporate Power & $\begin{array}{l}\text { - Tomorrow E Tomorrow [novel] Tom Sweterlitsch (2014) } \\
\text { - Space Merchants [novel] Frederik Phol \& Cyril M. Kornbluth (1953) } \\
\text { - Simulacron-3 [novel] Daniel F. Galouys (1964) }\end{array}$ \\
\hline Hubris, Breakdown \& the End of Big Data & $\begin{array}{l}\text { - The Machine Stops [novel] Edward M. Forster (1909) } \\
\text { - Frankenstein [novel] Mary Shelley (2012) } \\
\text { - The End of Big Data [short story] James Bridle (2016) }\end{array}$ \\
\hline
\end{tabular}

Final considerations
As indicated, the above overview of speculative datafictions is neither comprehensive nor conclusive. Rather, it is meant as an initial guide and orientation, an invitation to dig deeper and explore a growing body of literary and audio-visual texts relevant to the subject matter. What also needs to be noted is that the proposed sub-categories (surveillance, social sorting, prediction, etc.) should be treated as only a suggestion, as but one attempt to cluster works of fiction that are so varied and rich that they could be interpreted, linked, and grouped in many different ways. Thus, while in a sense we engage in the precarious process of "sorting things out" [Bowker and Star, 1999], we seek to do so in an open and preliminary manner, providing a basis for further discussion rather than a definitive scheme or structure.

Questions of categorization aside, the overview should have conveyed a sense of the thematic breadth and scope covered by datafictions, but also of the ways these visions connect to issues around Big Data and algorithmic decision making. Going forward, we see two main application areas for this kind of sci-fi engagement: First, as often argued in the academic literature [e.g., see Berne and Schummer, 2005], narrative fiction can prove fertile ground for exploring social, ethical, and political issues around new and emerging technologies, thereby supporting educational efforts and the cultivation of reflective capacities in students, scholars, and practitioners. As Burton and co-authors [2015, p. 35] contend, by "reframing 
recognizable human situations and problems in terms of unfamiliar settings and technology, science fiction [...] can be an ideal medium for raising and exploring ethical concerns", making "visible the alarming and problematic aspects of a given situation that have become invisible in the mundane world because they have come to be regarded as ordinary or inevitable." From this perspective, works of fiction can serve as a valuable tool for supporting critical thinking across educational, democratic, and innovation settings - a way to draw people in and stimulate public debate [e.g., see Macnaghten, Davies and Kearnes, 2015; Reinsborough, 2017; Rousell, Cutter-Mackenzie and Foster, 2017]. We concur with this perspective and would add that there is further need for shared collections and repositories that could facilitate the preparation of e.g. workshops and courses. The present article can be seen as an attempt to contribute to this effort. There is, however, a second area of application that tends to receive far less attention. Educational and public engagement efforts aside, speculative fictions can also be used to examine how techno-scientific innovations are perceived at a given point in time as well as what is ultimately regarded as a desirable or undesirable future. Watching episodes of the British TV series Black Mirror, for instance, may give an impression of how specific technologies are culturally imagined and what kind of futures are considered plausible given current implementations and trajectories. In this regard, we recognize speculative fictions as valuable objects of research, conceptually no less legitimate and credible than other forms of future-oriented technology assessment such as mapping exercises, scenario development, or Delphi surveys. While such modes of producing anticipatory knowledge assemble expert opinions or rely on deliberative methods, speculative fiction is most useful as a relatively unrestricted form of creative visioning. As such, it can expand the spectrum of what can reasonably be imagined, enabling comparative analysis between dominant and counter discourses [see Hajer, 2006], and possibly even serve as a necessary corrective to political and industry hyperbole [see Rieder, 2018]. In that sense, speculative fictions do not just imagine futures, but envision alternative paths and realities that can challenge the agenda-driven storylines of public-private stakeholders. We thus belief that a responsible research and innovation process should take into consideration the visions and worries put forth in speculative fictions, acknowledging the genre as a fruitful site for investigating broader cultural narratives and imaginations.

As mentioned, we hope that this paper marks only the beginning of more consistent academic interest in what we propose to call datafictions. The time seems right as processes of computerization and datafication continue to pose considerable social, ethical, and political challenges - from security to privacy to algorithmic bias and discrimination. There is no lack of relevant material: besides a proliferation of genre-specific publications, the fictional treatment of speculative data cultures has entered the mainstream. Jonathan Franzen's [2015] novel Purity, for example, can easily be regarded a datafiction from a 'serious', critically acclaimed author whose work would usually not be placed in, or even near, the science fiction genre. If one also takes into consideration that recent movies from the Marvel superhero universe feature visually striking examples of data-driven decision making — think of Project Insight in Captain America: The Winter Solider [2014] or Peter Parker's AI suite in Spider-Man: Homecoming [2017] — it becomes clear that datafictions no longer linger at the periphery of popular culture, but right at the center of modern society's collective imagination. 
Adams, V., Murphy, M. and Clarke, A. E. (2009). 'Anticipation: technoscience, life, affect, temporality'. Subjectivity 28 (1), pp. 246-265. https://doi.org/10.1057/sub.2009.18.

Andrews, M. A. (25th January 2017). 'Sales of Orwell's '1984' spike after Kellyanne Conway's 'alternative facts". The Washington Post. [online]. URL: http: //wapo.st/2jdDYYk?tid=ss_tw\&utm_term=.382224a84ac1 (visited on 22nd November 2019).

Asimov, I. (2010a). Foundation. Original publication year (1951). New York, NY, U.S.A.: Random House.

- (2010b). Foundation and empire. Original publication year (1952). New York, NY, U.S.A.: Random House.

- (2010c). Second foundation. Original publication year (1953). New York, NY, U.S.A.: Random House.

Atwood, M. (17th June 2005a). 'Aliens have taken the place of angels'. The Guardian. [online]. URL: https://www. theguardian.com/film/2005/jun/17/sciencefict ionfantasyandhorror margaretatwood (visited on 22nd November 2019).

— (2005b). Writing with intent. Essays, reviews, personal prose: 1983-2005. New York, NY, U.S.A.: Carroll \& Graf Publishers.

- (2011). In other worlds. SF and the human imagination. New York, NY, U.S.A.: Doubleday.

Ball, P. (2002). 'The physical modelling of society: a historical perspective'. Physica A: Statistical Mechanics and its Applications 314 (1-4), pp. 1-14. https://doi.org/10.1016/s0378-4371(02)01042-7.

Barben, D., Fisher, E., Selin, C. and Guston, D. (2008). 'Anticipatory Governance of Nanotechnology: Foresight, Engagement, and Integration'. In: Handbook of Science and Technology Studies. Ed. by E. J. Hackett, O. Amsterdamska, M. E. Lynch and J. Wajcman. 3rd ed. Cambridge, MA, U.S.A.: MIT Press, pp. 979-1000.

Bergstein, B. (24th October 2017). 'Fiction that gets AI right. What to watch and read before the robots take over'. MIT Technology Review. [online]. URL: https: //www.technologyreview.com/s/609131/fiction-that-gets-ai-right/ (visited on 22nd November 2019).

Berne, R. W. and Schummer, J. (2005). 'Teaching societal and ethical implications of nanotechnology to engineering students through science fiction'. Bulletin of Science, Technology \& Society 25 (6), pp. 459-468. https://doi.org/10.1177/0270467605283048.

Bowker, G. C. and Star, S. L. (1999). Sorting things out: classification and its consequences. Cambridge, MA, U.S.A.: MIT Press.

Boyd, D. M. and Crawford, K. (2012). 'Critical questions for big data'. Information, Communication \& Society 15 (5), pp. 662-679. https://doi.org/10.1080/1369118X.2012.678878.

Bridle, J. (28th January 2016). 'The end of big data'. Motherboard. [online]. URL: http $\mathrm{s}$ ://motherboard.vice.com/en_us/article/vv7ekm/the-end-of-big-data (visited on 22nd November 2019).

Burton, E., Goldsmith, J. and Mattei, N. (2015). 'Teaching AI ethics using science fiction'. In: Papers from the 2015 AAAI Workshop on Artificial Intelligence and Ethics. [online]. Palo Alto, CA, U.S.A.: AAAI Digital Library. URL: https://aaai .org/ocs/index.php/WS/AAAIW15/paper/view/10139 (visited on 22nd November 2019). 
Cadwalladr, C. and Graham-Harrison, E. (17th March 2018). 'Revealed: 50 million Facebook profiles harvested for Cambridge Analytica in major data breach'. The Guardian. [online]. URL: https://www . theguardian.com/news/2018/mar/17/ca mbridge-analytica-facebook-influence-us-election (visited on 22nd November 2019).

Callon, M., Lascoumes, P. and Barthe, Y. (2009). Acting in an uncertain world: an essay on technical democracy. Original publication year (2001). Cambridge, MA, U.S.A.: The MIT Press.

Cameron, J. (1984). The Terminator. [film]. U.S.A.

Chollet, F. (27th November 2017). 'The impossibility of intelligence explosion'. Medium. [online]. URL: https://medium.com/@articlefrancois. chollet/theimpossibility-of-intelligence-explosion-5be4a9eda6ec (visited on 22nd November 2019).

Citron, D. K. and Pasquale, F. (2014). 'The scored society: due process for automated decisions'. Washington Law Review 89 (1), pp. 1-33.

Collingridge, D. (1980). The Social Control of Technology. New York, U.S.A.: St. Martin's Press; London, U.K.: Pinter.

Collins, W. (1993). Computer one. London, U.K.: No Exit Press.

de Smedt, J. and de Cruz, H. (2015). 'The epistemic value of speculative fiction'. Midwest Studies In Philosophy 39 (1), pp. 58-77. https://doi.org/10.1111/misp.12035.

del Prado, G. M. (5th August 2015). 'Intelligent robots don't need to be conscious to turn against us'. Business Insider. [online].

URL: https://www . businessinsider.com/artificial-intelligence-machine -consciousness-expert-stuart-russell-future-ai-2015-7 (visited on 10th January 2020).

Dick, P. K. (1991). 'The minority report'. In: The collected stories of Philip K. Dick. Vol. 4. Original publication year (1956). New York, NY, U.S.A.: Citadel Press, pp. 71-102.

DLA Piper (2017). Data protection laws of the world. Handbook. URL: https : //www .dlapiperdataprotection.com/system/modules/za.co.heliosdesign.dla.lo tw. data_protection/functions/handbook.pdf?country=all (visited on 22nd November 2019).

Egan, M. F. (1889). 'Book-talk'. Lippincott's Monthly Magazine 44, pp. 597-598. Eggers, D. (2013). The circle. New York, NY, U.S.A.: Random House.

Felt, U. (2015). 'Keeping technologies out: sociotechnical imaginaries and the formation of a national technopolitical identity'. In: Dreamscapes of modernity. Sociotechnical imaginaries and the fabrication of power. Ed. by S. Jasanoff and S.-H. Kim. Chicago, IL, U.S.A.: University of Chicago Press, pp. 103-125. https://doi.org/10.7208/chicago/9780226276663.003.0005.

Ferguson, A. G. (2017). The rise of big data policing: surveillance, race, and the future of law enforcement. New York, NY, U.S.A.: New York University Press.

Forster, E. M. (2013). The machine stops. Original publication year (1909). Rockville, MD, U.S.A.: Wildside Press.

Franzen, J. (2015). Purity. New York, NY, U.S.A.: Picador.

Galouye, D. F. (1999). Simulacron-3. [Amazon Kindle edition]. Original publication year (1964). Rockville, MD, U.S.A.: ArcManor.

Garland, A. (2014). Ex Machina. [film]. U.K. 
Goodman, M. (2016). 'Chapter 4: you're not the customer, you're the product'. In: Future crimes. Inside the digital underground and the battle for our connected world. New York, NY, U.S.A.: Anchor Books, pp. 54-80.

Hajer, M. A. (2006). 'The living institutions of the EU: analysing governance as performance'. Perspectives on European Politics and Society 7 (1), pp. 41-55. https://doi.org/10.1080/15705850600839546.

Halpern, M. K., Sadowski, J., Eschrich, J., Finn, E. and Guston, D. H. (2016). 'Stitching together creativity and responsibility: interpreting Frankenstein across disciplines'. Bulletin of Science, Technology E Society 36 (1), pp. 49-57. https://doi.org/10.1177/0270467616646637.

Heinlein, R. A. (1989). 'March 4, 1949: Robert A. Heinlein to Lurton Blassingame'. [letter]. In: Grumbles from the grave. Ed. by R. A. Heinlein and V. Heinlein. New York, NY, U.S.A.: Ballantine Books.

Huxley, A. (2006). Brave new world. Original publication year (1932). New York, NY, U.S.A.: HarperCollins.

Jaruzelski, B., Staack, V. and Shinozaki, A. (2016). 'Global innovation 1000: software-as-a-catalyst'. strategy+business Winter (85), pp. 85-105. URL: https : //www. strategy-business. com/feature/Software-as-a-Catalyst.

Karinen, R. and Guston, D. H. (2010). 'Toward anticipatory governance: the experience with nanotechnology'. In: Governing future technologies. Nanotechnology and the rise of an assessment regime. Ed. by M. Kaiser, M. Kurath, S. Maasen and C. Rehmann-Sutter. Dordrecht, The Netherlands: Springer, pp. 217-232. https://doi .org/10.1007/978-90-481-2834-1_12.

Khanna, P. (15th March 2016). 'These 25 companies are more powerful than many countries'. Foreign Policy. [online].

URL: http://foreignpolicy.com/2016/03/15/these-25-companies-are-more -powerful-than-many-countries-multinational-corporate-wealth-power/ (visited on 22nd November 2019).

Kitchin, R. (2014). 'Big data, new epistemologies and paradigm shifts'. Big Data $\mathcal{E}$ Society 1 (1), pp. 1-12. https://doi .org/10.1177/2053951714528481.

Kovacic, Z., Strand, R. and Völker, T. (2019). The circular economy in Europe: critical perspectives on policies and imaginaries. New York, NY, U.S.A.: Routledge.

Krugman, P. (4th December 2012). 'Paul Krugman: Asimov's foundation novels grounded my economics'. The Guardian. [online]. URL: https: //www . theguardi an.com/books/2012/dec/04/paul-krugman-asimov-economics (visited on 22nd November 2019).

Kuźnicki, S. (2017). Margaret Atwood's dystopian fiction. Fire is being eaten. Newcastle, U.K.: Cambridge Scholars Publishing.

Le Guin, U. K. (29th August 2009). 'The year of the flood by Margaret Atwood'. The Guardian. [online]. URL: https://www. theguardian.com/books/2009/aug/29/m argaret-atwood-year-of-flood (visited on 22nd November 2019).

Liu, K. (2012). 'The perfect match'. Lightspeed (31). [online]. URL: http://www. lightspeedmagazine.com/fiction/the-perfect-match/ (visited on 22nd November 2019).

Lyon, D. (2014). 'Surveillance, Snowden, and big data: capacities, consequences, critique'. Big Data \& Society 1 (2), pp. 1-13. https://doi.org/10.1177/2053951714541861. 
Macnaghten, P., Davies, S. R. and Kearnes, M. (2015). ‘Understanding public responses to emerging technologies: a narrative approach'. Journal of Environmental Policy \& Planning, pp. 1-19. https://doi.org/10.1080/1523908x.2015.1053110.

Mayer-Schönberger, V. and Cukier, K. (2013). Big data. A revolution that will transform how we live, work, and think. New York, NY, U.S.A.: Houghton Mifflin Harcourt.

Michelson, E. S. (2016). Assessing the societal implications of emerging technologies. Anticipatory governance in practice. Abingdon, U.K. and New York, NY, U.S.A.: Routledge.

Milkoreit, M. (2017). 'Imaginary politics: climate change and making the future'. Elem Sci Anth 5 (62), pp. 1-18. https://doi .org/10.1525/elementa. 249.

Miller, R.-E. L. (2015). 'Impact assessment and science fiction: complementary ways to ask "what happens if...?" and the delineation of a new sub-genre'. Journal for Future Studies 20 (2), pp. 105-112.

URL: https://jfsdigital.org/2015-2/vol-20-no-2-dec-2015/article/forc ing-the-design-of-fictional-futures-from-theory-to-cases-implementa tion/essays-4/impact-assessment-and-science-fiction-complementary-w ays-to-ask-what-happens-if-and-the-delineation-of-a-new-sub-genre/.

Miner, M. (1991). “'Trust me": reading the romance plot in Margaret Atwood's The Handmaid's Tale'. Twentieth Century Literature 37 (2), p. 148. https://doi.org/10.2307/441844.

Mittelstadt, B. D., Allo, P., Taddeo, M., Wachter, S. and Floridi, L. (2016). 'The ethics of algorithms: mapping the debate'. Big Data \& Society 3 (2), pp. 1-21. https://doi.org/10.1177/2053951716679679.

O'Neil, C. (2016). Weapons of math destruction. How big data increases inequality and threatens democracy. New York, NY, U.S.A.: Crown.

Onyett, N. (2016). Study and revise for AS/A-level: The Handmaid's Tale by Margaret Atwood. London, U.K.: Hodder Education.

Orwell, G. (1987). Nineteen eighty-four. Original publication year (1949). London, U.K.: Penguin Books.

Pasquale, F. (2015). The black box society: The secret algorithms that control money and information. Boston, U.S.A.: Harvard University Press.

Patch, J. (2014). 'Science and fiction. A polemic on the role of imaginative fiction in civics and the economy of innovation'. In: Teaching towards democracy with postmodern and popular culture texts. Ed. by P. Paugh, T. Kress and R. Lake. Rotterdam, The Netherlands: Sense Publishers, pp. 179-199.

Pentland, S. (2014). Social physics. How good ideas spread - the lessons from a new science. New York, NY, U.S.A.: The Penguin Press.

Pereira, Â. G. and Funtowicz, S., eds. (2015). Science, philosophy and sustainability: the end of the Cartesian dream. London, U.K. and New York, NY, U.S.A.: Routledge.

Pohl, F. and Kornbluth, C. M. (2003). The space merchants. Original publication year (1953). London, U.K.: Orion Publishing.

Proyas, A. (2004). I, Robot. [film]. U.S.A.

Reggia, J. A. (2013). 'The rise of machine consciousness: studying consciousness with computational models'. Neural Networks 44, pp. 112-131. https://doi.org/10.1016/j.neunet.2013.03.011. 
Reinsborough, M. (2017). 'Science fiction and science futures: considering the role of fictions in public engagement and science communication work'. JCOM 16 (04), C07. https://doi .org/10.22323/2.16040307.

Rieder, G. (2018). 'Tracing big data imaginaries through public policy: the case of the European Commission'. In: The politics and policies of big data: big data, big brother? Ed. by A. R. Sætnan, I. Schneider and N. Green. New York, NY, U.S.A. and London, U.K.: Routledge, pp. 89-109.

Rieder, G. and Simon, J. (2016). 'Datatrust: or, the political quest for numerical evidence and the epistemologies of Big Data'. Big Data \& Society 3 (1), pp. 1-6. https://doi.org/10.1177/2053951716649398.

Rousell, D., Cutter-Mackenzie, A. and Foster, J. (2017). 'Children of an earth to come: speculative fiction, geophilosophy and climate change education research'. Educational Studies 53 (6), pp. 654-669. https://doi.org/10.1080/00131946.2017.1369086.

Russo, A. and Russo, J. (2014). Captain America: the winter soldier. [film]. U.S.A.

Sargent, J. (1970). Colossus: the Forbin project. [film]. U.S.A.

Selin, C. (2011). 'Negotiating plausibility: intervening in the future of nanotechnology'. Science and Engineering Ethics 17 (4), pp. 723-737. https://doi.org/10.1007/s11948-011-9315-x.

Shearlaw, M. (1st August 2016). 'Facebook lures Africa with free internet - but what is the hidden cost?' The Guardian. [online]. URL: https://www . theguardian.com/world/2016/aug/01/facebook-free-bas ics-internet-africa-mark-zuckerberg (visited on 22nd November 2019).

Shelley, M. (2012). Frankenstein. Original publication year (1818). New York, NY, U.S.A.: Barnes \& Noble.

Spielberg, S. (2001). A.I. Artificial Intelligence. [film]. U.S.A.

- (2002). Minority report. [film]. U.S.A.

Srivastava, A. and Thomson, S. B. (2009). 'Framework analysis: a qualitative methodology for applied policy research'. Journal of Administration and Governance 4 (2), pp. 72-79.

Strogatz, S. (2004). 'The physics of crowds'. Nature 428 (6981). [online], pp. 367-368. https://doi.org/10.1038/428367a. (Visited on 22nd November 2019).

Sturgeon, L. (2015). Data-fictions: data and its interface as a cultural artefact. [online]. U.K. URL: https://www . academia.edu/28445100/Data-Fictions_Data_and_it s_interface_as_a_cultural_artefact (visited on 22nd November 2019).

Sveck, M. and Winiski, M. (2013). 'SF and speculative novels. Confronting the science and the fiction'. In: Science fiction and speculative fiction. Challenging genres. Ed. by P. L. Thomas. Rotterdam, The Netherlands: Sense Publishers, pp. 34-57.

Sweterlitsch, T. (2014). Tomorrow and tomorrow. New York, NY, U.S.A.: G. P. Putnam's Sons.

Thomas, P. L. (2013). 'Introduction. Challenging science fiction and speculative fiction'. In: Science fiction and speculative fiction. Challenging genres. Ed. by P. L. Thomas. Rotterdam, The Netherlands: Sense Publishers, pp. 1-13. https://doi.org/10.1007/978-94-6209-380-5_1.

Toffler, A. (1970). Future shock. New York, NY, U.S.A.: Random House.

Ubukata, T. (2012). Psycho-pass. [television series]. Japan. 
Völker, T. (2020). 'Re-ordering science-society relations and re-distributing responsibility? On the participatory production and circulation of anticipatory knowledge in transdisciplinary sustainability research'. In: Science and society relations today: a sociological gaze. Ed. by A. Delicado, F. Crettaz Von Roten, A. Tupsala and I. Van der Weijden. Forthcoming. New York, NY, U.S.A.: Springer.

Wachowski, L. and Wachowski, L. (1999). The Matrix. [film]. U.S.A.

Watts, J. (2017). Spider-man: homecoming. [film]. U.S.A.

Wilson, D. H. (2011). Robopocalypse. New York, NY, U.S.A.: Doubleday.

Wilson, R. C. (2015). The affinities. New York, NY, U.S.A.: Tom Doherty Associates. Wright, J. (2016). Nosedive. Black Mirror episode [television series]. U.K.

Yeung, K. and Lodge, M., eds. (2019). Algorithmic regulation. Oxford, U.K.: Oxford University Press.

\section{Authors}

\section{How to cite}

Rieder, G. and Völker, T. (2020). 'Datafictions: or how measurements and predictive analytics rule imagined future worlds'. JCOM 19 (01), A02.

https://doi.org/10.22323/2.19010202. 